\title{
Empirical Study on Logistics Efficiency of Five Northwestern Provinces along the Silk Road Economic Belt
}

\author{
Yi Tianjiao \\ International Business School of Shaanxi Normal University \\ Xi'an, Shaanxi, China
}

\author{
Yan Yuxin \\ Xi an University of Architecture and Technology \\ Xi'an, Shaanxi, China
}

\begin{abstract}
There are five Northwestern provinces of China are located along the Silk Road Economic Belt, so it is of great significance to study the development level of logistics industry in this area. At the start of this article, we define the concept of logistics and logistics industry, and then we use logistics efficiency as an indicator to measure the development of the logistics industry in the five Northwestern provinces. With three input index and three output index, as well as the super efficiency DEA model, efficiency score of the logistics industry of the five provinces from 2007-2016 is calculated. The results show that the five provinces' logistics industry efficiency changes similarly every year, and as a whole, it changes with the macro economy of China. The logistics industry in Ningxia has the highest efficiency, and Gansu has experienced a remarkable decline in the past $\mathbf{1 0}$ years, the efficiency of Shaanxi, Xinjiang and Qinghai are quite stable and consistent.
\end{abstract}

Keywords-Logistics; Logistics efficiency; Silk Road Economic Belt; SE-DEA model; Development level

\section{INTRODUCTION}

With the globalization, international division and cooperation, the logistics industry has rapidly developed in recent years. The efficient development of the logistics industry is important to the construction of the Silk Road Economic Belt. With the policy of "communication, road link, trade flow, currency circulation, and cultural integration", the research of the logistics efficiency of the five northwestern provinces along the Silk Road Economic Belt is very meaningful to coordinate regional development, achieve the common prosperity, improve the well-being of the people's livelihood, and of course, it has practical significance to the further exploration of the "third profit source"[1-2]

\section{CORE CONCEPT AND DEFINITION}

\section{A. Logistics}

It is generally believed that the first appearance of the concept of logistics is in a thesis named Some Problems in Market Distribution written by the American scholar A.W. Shaw in 1915 in which he explained the circulation of markets [3]. With the development of economic globalization and international division, the connotation of the concept has accordingly changed. Its original name "physical distribution", has also changed to "logistics" which means the physical movement of the translated materials or commodities distinguished from the flow of commodity value. In the United States, Japan and other developed countries, the knowledge of logistics has changed from "traditional logistics" to "modern logistics"[4]. The Council of Supply Chain Management Professionals (CSCMP), which is the most authoritative academic organization of logistics in the United States, defined logistics as: the plan, implement and control of the effective and cost-effective flow and storage of raw materials, semifinished products, finished products and the related information from the producers to the consumers in order to meet customers' needs. It can be seen that modern logistics is the combination of the flow of goods and materials, the flow of value and the flow of information.

China first introduced the concept of logistics from Japan in the early 1980s. This definition has been used for a long time in China until the logistics terminology issued and implemented in August 2001[5]. The national standard of logistics terminology defines logistics as a process which combines the basic functions of transportation, storage, handling, handling, packing, circulation processing, distribution, information processing and other basic functions according to the actual needs. In 2006, this definition was revised as: the flow of goods from the supply area to the receiving place according to actual needs, in which it contains the organically combined basic functions such as transportation, storage, loading and unloading, handling, packaging, circulation processing, distribution, recycling, information processing and so on.

\section{B. Modern logistics industry}

Logistics industry involves all the logistics activities mentioned before and various logistics support activities. In the medium and long-term development of logistics industry planning (2014-2020) issued by the State Council, the logistics industry is defined as following: logistics is the integration of several industries such as transportation, warehousing, freight forwarding and information services industry [6-7]. It is a basic and strategic producer services industry which supports national economic development. In this paper, we make further definition of the major parts of the logistics industry: (1) the definition of the transportation mainly refers to the transport of goods, it includes railway freight, road freight industry, pipeline transportation, water freight, air freight, transportation and other auxiliary transportation industry. In consideration of the research object 
of this paper, the actual situation and availability of data, the freight transport industry in the empirical analysis below only includes railway freight transport industry and road freight transport industry. (2) The definition of warehousing in this paper refers to the business activities of storing and keeping goods on behalf of customers in warehouses, freight yards or other places. (3) The definition of freight forwarding is to accept the consignment from the shipper or the consignee, and act as the broker of consignor or with the name of their own, to handle cargo transportation and related business and receive compensation for services industries. As the freight forwarding industry does not have separate statistics, it is difficult to find relevant data, and some freight forwarding industry is already included in the postal administration industry, so the freight forwarding industry is not considered separately. (4) The information services industry in this article refers to the logistics information industry. According to the theory of logistics, information is a kind of material, the flow of information is same as the physical movement of other material. With transportation, storage, loading and unloading, handling, distribution processing, such as information transmission, storage, search, filter, etc., the flow of information is a kind of logistics. In this paper, information industry is composed by information transmission, computer service and software industry. (5) The postal industry is also included in the logistics industry. According to the Classification of National Economic Trades (GB/T 4754-2011), the postal industry refers to the communications business, which is mainly based on the transmission of letters, including basic postal services and Courier services, it is also part of the modern logistics industry.

\section{C. logistics efficiency}

There is no specific definition for the efficiency of the logistics industry up to now, a common method to measure the logistics efficiency is to use the ratio of logistics cost to GDP [8]. But as mentioned above, the development of modern logistics is more about improving the quality of the service rather than simply reduce costs because logistics activities are widely recognized to add considerable value of products. Therefore, we should measure the logistics efficiency from both cost efficiency and service quality. That means, how to realize the maximizing output given the limited input, so as to achieve Pareto efficiency. Therefore, in this paper, the logistics efficiency is defined as $E=$ Output/Input. In other words, the logistics industry efficiency is measured by the ratio of Output to Input.

\section{LOGISTICS EFFICIENCY MEASUREMENT OF FIVE NORTHWESTERN PROVINCES}

\section{A. SE-DEA model}

The SE-DEA model is short for super-efficiency data envelopment analysis, it is based on the CCR model which is the most common way to be used in all of the DEA models. Unlike CCR model, the SE-DEA model changes the way to evaluate DMU efficiency. To be specific, in the CCR model, we use all the DMUs to build the production frontier, and we measure the efficiency of the DMU by calculating the relative distance from the certain DMU to the frontier. But in the SEDEA model, when a certain DMU is evaluated, it is excluded from the production possible set, so the production frontier is constructed with only the rest of DMUs, the way to calculate the efficiency is the same, but we get the different results than the classic way because clearly the frontier has changed. On the one hand, the advantage of this approach is to avoid the case in which too many DMUs score 1 that we can't compare. The SE-DEA model enable us to differentiate and compare the DMUs that are already efficient. On the other hand, as for the originally non-efficient DMUs in the SE-DEA model, they don't participate in constructing the production frontier at first, so the frontier for them are still the same with that in the CCR model. In summary, the SE-DEA model relieves the original efficient DMUs from restraint limit of the efficiency score without changing the non-efficient DMUs efficiency score.

\section{B. Indicators and sample selection}

Reasonable selection of the indicators is of vital importance to the DEA model. In the previous study on the logistics efficiency, different indicators have been used due to different research directions and goals. Considering the systematization, comprehensiveness, importance, objectivity and availability of the indicators, the three output indicators and three input indicators are chosen and listed in Table 1.

TABLE I. INDICATORS OF THE DEA MODEL

\begin{tabular}{|c|r|}
\hline \multicolumn{1}{|c|}{ Type of Indicators } & Contentof Indicators \\
\hline \multirow{2}{*}{ Output index } & Output value of the logistics industry(100 million yuan) \\
\cline { 2 - 2 } & Freight volume(10000 tons) \\
\cline { 2 - 2 } Input index & Ton-Kilometers of Freight(100 million Ton-Kilometers) \\
\cline { 2 - 2 } & Lengthof road and railway(10000 kilometers ) \\
\cline { 2 - 3 } & fixed assets investment(100 million yuan) \\
\cline { 2 - 3 }
\end{tabular}


As it's already shown, we chose the six indicators above, collected the data of 2007-2016 of the five northwestern provinces as samples. All the required data is from 2007-2016 China statistical yearbook and the statistical year book of the five northwestern provinces.

\section{Results}

Due to the large amount of initial data, it is inconvenient to present it all in the paper. But it is welcome to contact the author to obtain the data. Provinces with different years are divided into different DMUs, the SE-DEA model that we use are based on the input, and it's under the assumption of variable returns to scale. The calculation is carried out with the help of EMS1.3 software, and the results are in the following Table 2.

TABLE II. RESULTS OF SE-DEA MODEL

\begin{tabular}{|c|c|c|c|c|c|c|}
\hline Year & Shaanxi & Gansu & Qinghai & Ningxia & Xinjiang & Average \\
\hline 2007 & 0.48 & 1.00 & 0.27 & 0.78 & 0.59 & 0.63 \\
\hline 2008 & 0.47 & 1.25 & 0.33 & 1.06 & 0.51 & 0.72 \\
\hline 2010 & 0.46 & 0.77 & 0.36 & 0.92 & 0.37 & 0.58 \\
\hline 2011 & 0.52 & 0.77 & 0.39 & 0.97 & 0.39 & 0.61 \\
\hline 2013 & 0.56 & 0.63 & 0.32 & 0.94 & 0.40 & 0.57 \\
\hline 2014 & 0.62 & 0.68 & 0.42 & 0.91 & 0.50 & 0.62 \\
\hline 2015 & 0.58 & 0.59 & 0.38 & 0.97 & 0.58 & 0.62 \\
\hline 2016 & 0.62 & 0.57 & 0.40 & 1.02 & 0.62 & 0.65 \\
\hline
\end{tabular}

It can be seen that only 5 DMUs are efficient, among them, the highest is 1.25 and the lowest is 1 . As for the non-efficient ones, the lowest of them is 0.27 . Generally speaking, the average efficiency score of all DMUs is 0.63 , the median is
0.58 , and the variance is 0.061 . According to the average of all five northwestern provinces which is also shown in the Fig.1. There is a slow rising trend overall except for two drops in 2009 and 2013.

\section{Average of all five provinces}

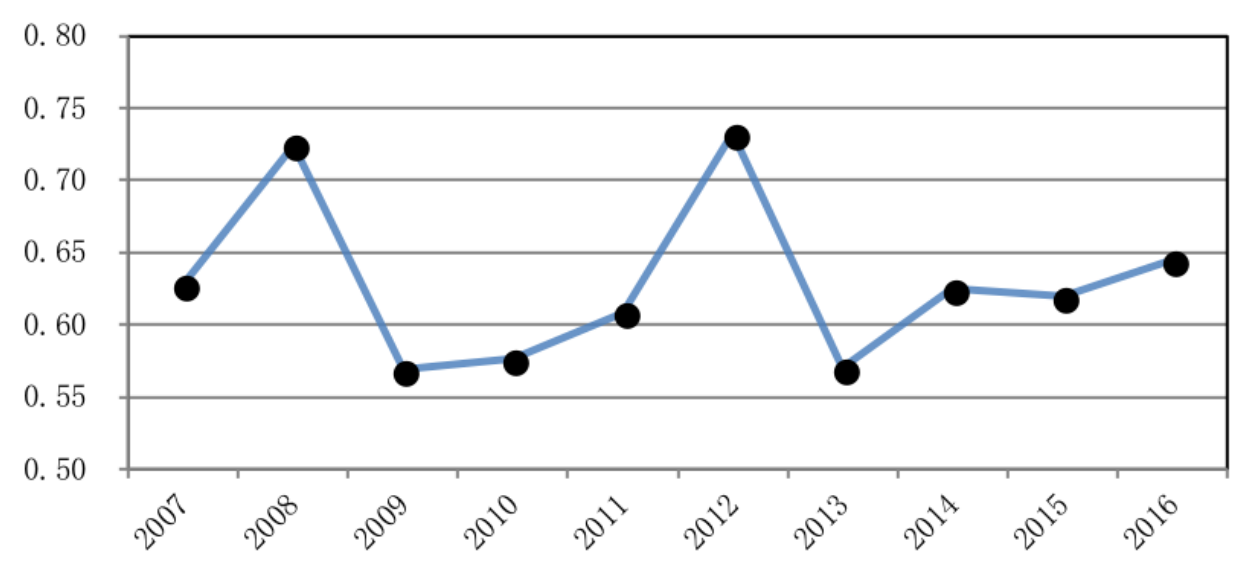

Fig. 1. Average of all five provinces

Compared with the average score of the whole period, we ranked the five provinces from high to low as following: Ningxia (0.96), Gansu (0.79), Shaanxi (0.54), Xinjiang (0.49) and Qinghai (0.37). Among them, the efficiency score of Gansu Province fluctuated the most among the five provinces between different years, and the variance of the efficiency score of Gansu reached 0.043 , the overall score started to fall after 2008. The average level of Ningxia is the highest, it kept rising in most of the years except for 2009 and 2013. As for Shaanxi and Xinjiang, the changes are similar. They both declined before 2009, and Xinjiang has fallen considerably, then the score of these two provinces rose steadily between 2009-2012. After sliding in 2012, the score of two provinces turned to increase again. The efficiency score of Qinghai 
province is the lowest among the five provinces. The variance is only 0.004 so the fluctuation is also the smallest. It kept increasing before the fall in 2012, and then rose to 0.4 after 2012, and kept this level in the following years. Although there is a certain gap in the efficiency score between the five provinces, but generally the trend is similar. In 2009 and 2013, there were declines in different degree, but by analyzing the input and output data, it can be found that the investment level is still rising compared with the previous year. However, the output remained unchanged or even slightly decreased. The main cause of this phenomenon is the global financial crisis in 2008, and the resulting economic downturn generated a negative impact on the logistics demand. In response, China has issued a package of macroeconomic and monetary policies to boost the economy, such as the four trillion investment plan, etc. These measures have maintained domestic demand to a certain level, as a result, the investment factors such as fixed assets investment were still increasing in the past two years. However, this effect didn't last after the year of 2012. In 2013, the economy of China has begun to decline again, and the efficiency of the logistics industry has fallen due to the demand shock.

\section{CONCLUSION}

In the future, the logistics industry in the five northwestern provinces will meet the perfect opportunity. Viewed from demand, the consumption scale of Chinese residents is expanding. In particular, the potential consumption of rural residents will gradually increase with the Rural Revitalization Strategy and Poverty Alleviation Strategy. At the same time, people's demand for the commodity services will be more diversified, and E-Commerce (Electronic Commerce) and Cross-Border E-Commerce and other emerging business mode will develop rapidly, which will create a vast market space for the logistics industry. At the national strategy level, the construction of Silk Road Economic Belt will bring more investment, human capital flow and infrastructure construction for the logistics industry in the five northwestern provinces. In the era of "Internet +", the logistics industry should make full use of cloud computing, big data, cyber-physical-system, satellite navigation, automatic sorting, intelligent transportation, unmanned aerial vehicle and other new generation of information technology. The new energy technology will accelerate the green transformation of logistics industry. The type of business and the added value of the modern logistics industry will continue to be promoted by the constantly improved standardization system, the favorable circumstance of business and highly simplified administrative formalities. All of that will provide guarantees for the development of the logistics industry.

\section{ACKNOWLEDGMENT}

I would like to express my gratitude to all those who helped me during the writing of this thesis. First, I would like to acknowledge and extend my sincere gratitude to my supervisor-Professor Wang Qinmei, for her encouragement, patient guidance, generous assistance and invaluable advice. Without her consistent and illuminating instruction, this article could not have finished. Secondly, I also want to thank my friends and my fellow classmates who gave me their help to sort out my problems and listened to me during the most difficult time. Last but not the least, my gratitude also extends to my family members who have been assisting, supporting and taking care of me all of my life.

\section{REFERENCES}

[1] ASEM - the modern Silk Road: travelling ideas for education reforms and partnerships between Asia and Europe[J]. QueAnh Dang. Comparative Education . 2013 (1)

[2] The broader effects of transportation infrastructure: Spatial econometrics and productivity approaches $[\mathrm{J}]$. Jeffrey P. Cohen. Transportation Research Part E. 2009 (3)

[3] Evaluating the efficiency of 3PL logistics operations[J]. Amer Hamdan,K.J. (Jamie) Rogers. International Journal of Production Economics . 2007 (1)

[4] Evaluating the Performance of Third - Party Logistics Arrangements: A Relationship Marketing Perspective[J] . A. MichaelKnemeyer,Paul R.Murphy. Journal of Supply Chain Management . 2006 (1)

[5] Evaluating the Performance of Third - Party Logistics Arrangements: A Relationship Marketing Perspective[J] . A. MichaelKnemeyer,Paul R.Murphy. Journal of Supply Chain Management . 2006 (1)

[6] A data envelopment analysis approach to measuring vendor performance $[J]$. Charles A. Weber. Supply Chain Management: An International Journal . 1996 (1)

[7] ManagingReverse Logistics Channels with Data Envelopment Analysis. David A Haas,,Frederic H Murphy,Richard A lancioni. Transportation Journal . 2003

[8] The Measurement of Efficiency of Portuguese Seaport Authorities with DEA. Barros,C.P. International Journal of Transport Economics . 2003 